\title{
ORIGINAL ARTICLE \\ EPIDEMIOLOGY OF URINARY TRACT INFECTIONS IN THE CHILDREN IN ZAGAZIG UNIVERSITY CHILDREN'S HOSPITAL
}

\author{
Ali Mohamed Abo zaid, Ezzat Kamel Amin, Abd El Rahman Ismail Kotb Mohamed *
}

Pediatric Department, Faculty of Medicine, Zagazig University,Zagazig, Egypt

\author{
*Corresponding auther : Abd \\ El Rahman Ismail Kotb \\ Mohamed \\ Pediatric Department, Faculty \\ of Medicine, Zagazig \\ University,Zagazig, Egypt
}

Email:abdoismailkotb@gmail.com

$\begin{array}{ll}\text { Submit Date } & 2019-03-29 \\ \text { Revise Date } & 2019-05-27 \\ \text { Accept Date } & 2019-05-28\end{array}$

\begin{abstract}
Background: The most common bacterial infection among children is Urinary Tract Infection (UTI). Early diagnosis and good treatment of UTI is very important as the risk of renal damage is increased in children below the age of five years which result of morbidity. The aim of this study was to estimate the prevalence of urinary tract infection (UTI) in children attending Pediatric outpatient clinic in Zagazig University Children's Hospital. Also to determine related risk factors, isolate the organisms that cause UTI in children and antibiotics susceptibility patterns. Methods: This Cross sectional descriptive study, was conducted on 600 children, ( 377 males and 223 females) from two to seven years old attending to pediatric outpatient clinic ZUH, All patient groups were exposed to full medical history, physical examination, Dipstick analysis by using both nitrite and leukocyte esterase detector, Microscopic examinations and urine culture for positive cases.
\end{abstract}

Results: The prevalence of UTI between children included in the current study was (7\%). LE positive were $56(9.3 \%)$, Nitrite positive were 47 (7.8\%) and both LE and Nitrite positive were 17 (2.8\%). Conclusion: The prevalence of UTI was $7 \%$ in our study, E - Coli was detected to be the most common organism, Cefotaxime and Amikacin were detected to be the most common antibiotic sensitive to the isolates.

Keywords: Urinary tract infection, urine culture, nitrite and leukocyte esterase.

\section{INTRODUCTION}

T The most common bacterial infection between children is Urinary Tract Infection (UTI). [1].

It was found that Eight percent of girls and two percent of boys are affected UTI by the age of 7 years according to recent studies[2].

Early diagnosis and treatment of UTI is very important due the risk of renal disease is increased in children below the age of 5 years which result of morbidity[3].

Congenital and functional abnormalities are the main factors which cause UTI among children and therefore accurate diagnosis, treatment, and follow up is important to prevent complications[4].

Initial lab investigation to confirm diagnosis of UTI, is an uncontaminated urine sample, which is challenging to collect from infants and children who are not toilet trained[5].

The standard investigation for diagnosis UTI is a urine culture but requires trained staff and specialized equipment for interpretation of results, therefore urine dipstick test is the best initial test because it is inexpensive and time saving when it comes to starting of treatment of UTI, Also it can be performed in small laboratories by lab technicians with minimum training[6].

It's important for physicians to know the 
prevalence of UTI in children of different age groups so they can select children for further diagnostic investigation and management[7].

The aim of this work was to detect the prevalence of urinary tract infection (UTI) in children attending Pediatric outpatient clinic in Zagazig University Children's Hospital. Also to determine, related risk factors, isolate the organisms that lead to UTI in children and antibiotics sensitivity patterns of the isolates.

\section{METHODS}

Site of the study: This study was carried out in the pediatric outpatient clinic in Zagazig University Children's Hospital.

Type of the study: Cross sectional descriptive study.

Sample size: Assuming that total population 6000 (50 cases in a day, five days of working in a week, 1000 cases in a month and 6000 cases in six months) and frequency of UTI in Egypt $11.4 \%$ according to study of $(\mathbf{8})$, power of test $80 \%$, confidence interval $95 \%$, the sample size is 600 patients, calculated by epinfo software package version 6 .

\section{Inclusion criteria:}

Children were selected in random way considered legible for entry into the study as they met these criteria:

1- Age from 2 - 7 years old. Live in Sharkia Governorate

2- Attended to Pediatric outpatient clinic in Zagazig University Children's Hospital.

\section{Exclusion criteria:}

1- Age below 2 years old and above 7 years old.

2- A child with a catheter associated UTI.

3- A child diagnosed with congenital anomalies.

4- Previous surgery of the genitourinary tract (except circumcision in male children)

5- A child has history of chronic renal diseases and found an immune compromising agents

as HIV, malignancy, chronic use of corticosteroids or other immunosuppressive drugs).

Administrative design: Approval was obtained From Zagazig University Institutional Review Board (ZU-IRB 3303/8-1-2017).

Written informed consent was obtained from all participants' parents and the study was approved by the research ethical committee of Faculty of Medicine, Zagazig University. The work has been carried out in accordance with The Code of Ethics of the World Medical Association (Declaration of Helsinki) for studies involving humans.

All parents accepted the study and no one rejected the study.

\section{Methods:}

All the included children in the study were exposed to the following:

1- Detailed history taking With special focus on the presence of urological manifestations (dysuria, loin pain, frequency, supra-pubic pain, change of the color of urine, enuresis), treatment with certain drugs for long period, past history of renal diseases or family history of renal diseases.

2- Full Clinical examination: With special focus on weight, height and abdominal examination for renal masses.

3- Urine samples from children Collected by midstream clean catch urine sample in sterile cups then complete urine analysis were done on this urine specimens by Microscopic examinations where centrifuged urine was examined microscopically for pus cells, WBCs and RBCs morphology. Dipsticks analysis by using both esterase and nitrate detectors.

4- Urine culture was done to positive cases.

\section{STATISTICAL ANALYSIS}

All data were analyzed using Minitab 17.0 statistical software (Minitab Inc., Pennsylvania, USA). Continuous variables were expressed as the mean $\pm \mathrm{SD}$, and the categorical variables were expressed as a number(percentage).

Continuous variables were checked for normality by using Shapiro-Wilk test. Independent sample Student's t-test was used to compare two groups of normally distributed data while ANOVA test was used to compare two independent measurements of normally distributed data in more than 2 groups.

All tests were two sided. $\mathrm{P}<0.05$ was considered statistically significant (Sig.), $\mathrm{p}<0.01$ was considered highly statistically significant (HS), and $\mathrm{p} \geq 0.05$ was considered nonstatistically significant (NS). 


\section{RESULT}

The prevalence of UTI among children included in our study was $(7 \%)$. LE positive were $56(9.3 \%)$, Nitrite positive were $47(7.8 \%)$ and both LE and Nitrite positive were 17 $(2.8 \%)$.

\section{Results of tables and figures :}

Table 1: shows that there was statistically significant difference between males and females in relation to prevalence of UTI, where the prevalence of UTI in female $54.8 \%$ (23 female from 42 one has UTI) while the prevalence of UTI in male 45.2\% (19 male from 42 one has UTI) $(\mathrm{P}=0.014)$.

Table 2: shows that there was statistically significant difference between Risk factors as Un- circumcised males, Prolonged use of antibiotics, Family history of UTI, Recurrent UTI, Enuresis, and Constipation in relation to prevalence of UTI.

Table 3: shows the relationship between both dipstick results and urine culture results in patients submitted to urine culture regarding UTI:
42 children had positive culture: regarding to dipstick results, 31 had positive LE, 28 children had positive nitrite and 17 children had positive both nitrite and LE.

On the other hand, 558 children had negative urine culture: regarding to dipstick results, 25 had positive LE, 19 children had positive nitrite and no children had both LE and nitrite.

Figure 1: shows that in the current study, 7\% of the patients had UTI, and $93 \%$ did not have UTI.

Figure 2: shows that according to culture, the infecting organisms were E.coli in (76\%), Klebsiella pneumonia in $(10 \%)$, Enterococcus Faecalis in (7\%), Proteus mirabilis in (5\%) and coagulase -ve staphylococci in $1(2 \%)$.

Figure 3: shows that according to antibiotic sensitivity, $(29 \%)$ patients were sensitive to Cefotaxime, (26\%) were sensitive to Amikacin, (14\%) were sensitive to Amoxicillin and Clavulanic acid, (7\%) were sensitive to Ceftriaxone, (7\%) were sensitive to Co Trimoxazole, $(7 \%)$ were sensitive to Imipenem, (5\%) were sensitive to Ciprofloxacin and (5\%) were sensitive to Nitrofurantoin.

Table (1): Relationship between sex and prevalence of UTI in the studied cases

\begin{tabular}{|c|c|c|c|c|c|c|c|c|}
\hline \multirow[t]{3}{*}{ Sex } & \multicolumn{4}{|c|}{ UTI } & \multirow{2}{*}{\multicolumn{2}{|c|}{ Total }} & \multirow[t]{3}{*}{ Test $^{\ddagger}$} & \multirow{3}{*}{$\begin{array}{l}\text { p-value } \\
\text { (Sig.) }\end{array}$} \\
\hline & \multicolumn{2}{|c|}{ Negative UTI } & \multicolumn{2}{|c|}{ Positive UTI } & & & & \\
\hline & No. & $\%$ & No. & $\%$ & No. & $\%$ & & \\
\hline Female & 200 & $35.8 \%$ & 23 & $54.8 \%$ & 223 & $37.2 \%$ & 5.987 & $\begin{array}{l}\text { 0.014 } \\
\text { (S) }\end{array}$ \\
\hline Male & 358 & $64.2 \%$ & 19 & $45.2 \%$ & 377 & $62.8 \%$ & & \\
\hline Total & 558 & $93 \%$ & 42 & $7 \%$ & 600 & $100 \%$ & & \\
\hline
\end{tabular}


Table (2):Risk factors for UTI in the studied population.

\begin{tabular}{|c|c|c|c|c|c|c|c|c|c|}
\hline \multirow[t]{3}{*}{ Risk factors } & & \multirow{2}{*}{\multicolumn{2}{|c|}{$\begin{array}{l}\text { Total } \\
(\mathrm{N}=600)\end{array}$}} & \multicolumn{4}{|c|}{ UTI } & \multirow[t]{3}{*}{ Test } & \multirow{3}{*}{$\begin{array}{l}\text { P-value } \\
\text { (Sig.) }\end{array}$} \\
\hline & & & & \multicolumn{2}{|c|}{$\begin{array}{l}\text { Negative UTI } \\
(\mathrm{N}=558)\end{array}$} & \multicolumn{2}{|c|}{$\begin{array}{l}\text { Positive UTI } \\
(\mathrm{N}=42)\end{array}$} & & \\
\hline & & No. & $\%$ & No. & $\%$ & No. & $\%$ & & \\
\hline \multirow{2}{*}{$\begin{array}{l}\text { Un circumcised } \\
\text { Males }\end{array}$} & Absent & 594 & $99 \%$ & 555 & $93.4 \%$ & 39 & $6.6 \%$ & \multirow{2}{*}{$\begin{array}{l}17.21 \\
4\end{array}$} & \multirow{2}{*}{$\begin{array}{l}0.006 \\
(\mathbf{S})\end{array}$} \\
\hline & Present & 6 & $1 \%$ & 3 & $50 \%$ & 3 & $50 \%$ & & \\
\hline \multirow{2}{*}{$\begin{array}{l}\text { Prolonged use of } \\
\text { antibiotics }\end{array}$} & Absent & 579 & $96.5 \%$ & 547 & $94.5 \%$ & 32 & $5.5 \%$ & \multirow{2}{*}{$\begin{array}{l}55.15 \\
3\end{array}$} & \multirow{2}{*}{$\begin{array}{l}<0.001 \\
(\mathrm{HS})\end{array}$} \\
\hline & Present & 21 & $3.5 \%$ & 11 & $52.4 \%$ & 10 & $47.6 \%$ & & \\
\hline \multirow{2}{*}{$\begin{array}{l}\text { Family history } \\
\text { of UTI }\end{array}$} & Absent & 595 & $99.2 \%$ & 555 & $93.3 \%$ & 40 & $6.7 \%$ & \multirow[t]{2}{*}{8.434} & \multirow{2}{*}{$\begin{array}{l}0.042 \\
(\mathrm{~S})\end{array}$} \\
\hline & Present & 5 & $0.8 \%$ & 3 & $60 \%$ & 2 & $40 \%$ & & \\
\hline \multirow[t]{2}{*}{ Recurrent UTI } & Absent & 586 & $97.7 \%$ & 549 & $93.7 \%$ & 37 & $6.3 \%$ & \multirow{2}{*}{$\begin{array}{l}18.15 \\
5\end{array}$} & \multirow{2}{*}{$\begin{array}{l}0.002 \\
(\mathrm{~S})\end{array}$} \\
\hline & Present & 14 & $2.3 \%$ & 9 & $64.3 \%$ & 5 & $35.7 \%$ & & \\
\hline \multirow[t]{2}{*}{ Enuresis } & Absent & 554 & $92.3 \%$ & 521 & $94 \%$ & 33 & $6 \%$ & \multirow{2}{*}{$\begin{array}{l}12.08 \\
3\end{array}$} & \multirow{2}{*}{$\begin{array}{l}0.003 \\
(\mathbf{S})\end{array}$} \\
\hline & Present & 46 & $7.7 \%$ & 37 & $80.4 \%$ & 9 & $19.6 \%$ & & \\
\hline \multirow[t]{2}{*}{ Constipation } & Absent & 562 & $93.7 \%$ & 526 & $93.6 \%$ & 36 & $6.4 \%$ & \multirow[t]{2}{*}{4.814} & \multirow{2}{*}{$\begin{array}{l}\text { 0.041 } \\
\text { (S) }\end{array}$} \\
\hline & Present & 38 & $6.3 \%$ & 32 & $84.2 \%$ & 6 & $15.8 \%$ & & \\
\hline
\end{tabular}

Table (3) Specificity and sensitivity of multi-stick method in relation to culture methods regarding UTI.

\begin{tabular}{|llllll|}
\hline & Sensitivity & Specificity & NPV & PPV & $\begin{array}{l}\text { Overall } \\
\text { accuracy }\end{array}$ \\
\hline LE & $\mathbf{7 3 . 8 \%}$ & $\mathbf{9 5 . 5 \%}$ & $\mathbf{9 8 \%}$ & $\mathbf{5 5 . 4 \%}$ & $\mathbf{9 4 \%}$ \\
\hline Nitrite & $\mathbf{6 6 . 7 \%}$ & $\mathbf{9 6 . 6 \%}$ & $\mathbf{9 7 . 5 \%}$ & $\mathbf{5 9 . 6 \%}$ & $\mathbf{9 4 . 5 \%}$ \\
\hline LE \& Nitrite & $\mathbf{4 0 . 5 \%}$ & $\mathbf{1 0 0 \%}$ & $\mathbf{9 5 . 7 \%}$ & $\mathbf{1 0 0 \%}$ & $\mathbf{9 5 . 8 \%}$ \\
\hline
\end{tabular}

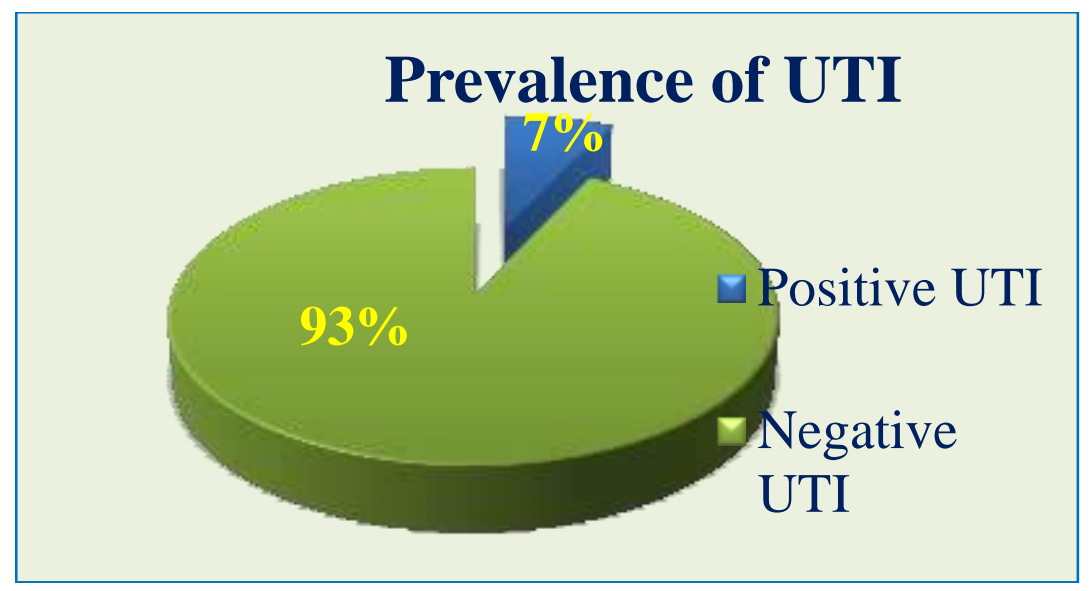

Figure 1. The prevalence of UTI 


\section{Figure 2. Infecting organisms in children with positive urine culture.}

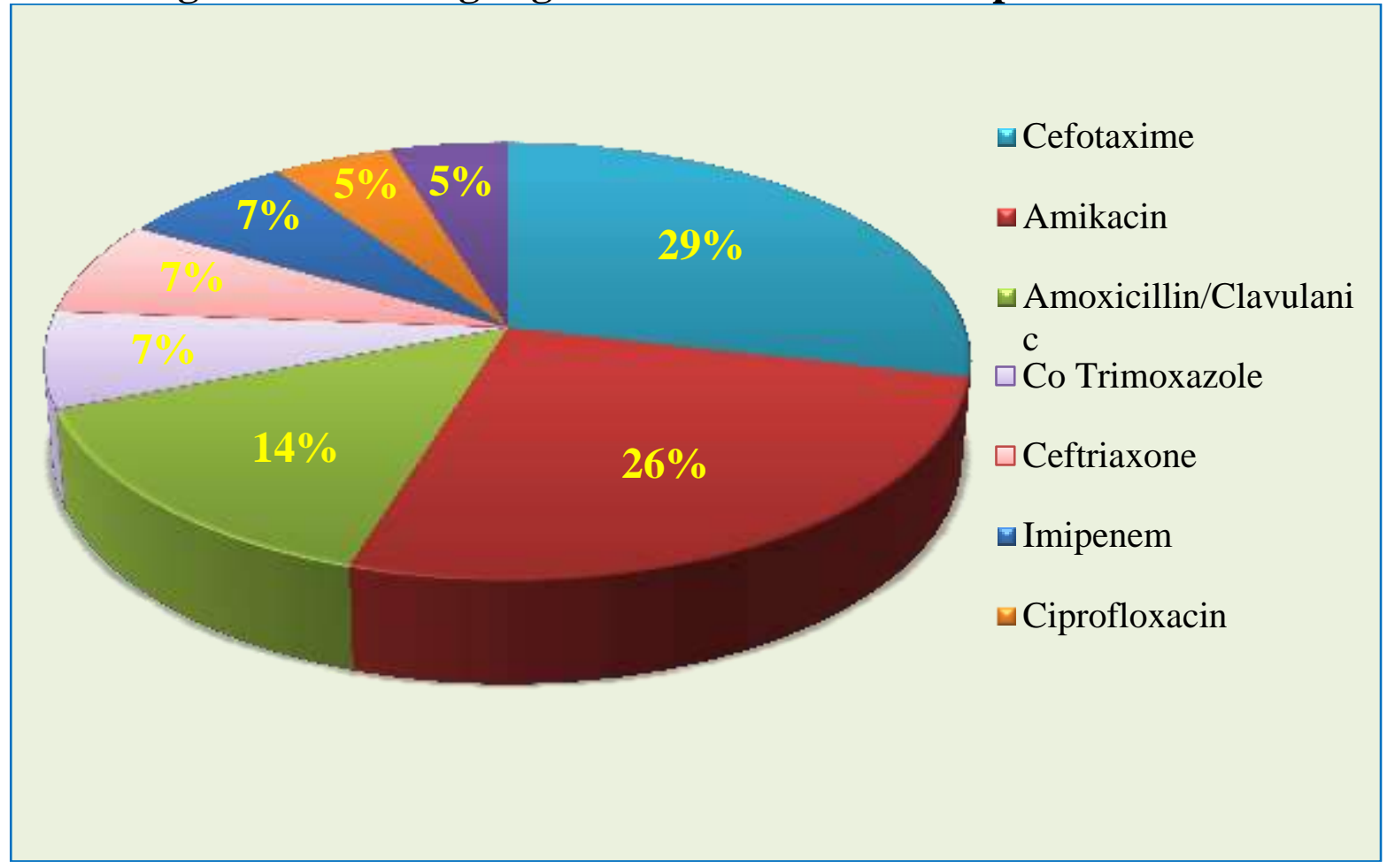

Figure 3. Percentage of distribution of antibiotic sensitivity.

\section{DISCUSSION}

This study was an attempt to determine the prevalence of urinary tract infection, microbial pathogens implicated in urinary tract infection and their antibiotic susceptibility patterns in children attended to pediatric outpatient clinic at Zagazig University Children's Hospital.The total number of children included in this study was 600 children from age 2-7 years , 377 child
$(62.8 \%)$ were males and 223 child $(37.2 \%)$ were females, 179 child (29.8\%) from urban areas and 421 child $(70.2 \%)$ from rural areas.

This study shows that the prevalence of urinary tract infection in children attended to pediatric outpatient clinic at Zagazig University Children's Hospital was 42 (7\%) child from 600 child included in this study.

Similar to our results [8], In Giza governorate in Egypt found that the Prevalence 
of UTI of 1000 apparently healthy school going children, 552 boys $(55.2 \%)$ and 448 girls (44.8\%), were enrolled in this cross sectional prevalence survey was $6 \%$ among school aged children.

In the study of [9], in Bosnia and found that UTI was present $352(6.5 \%)$ children, among those $114(32.4 \%)$ were boys and $238(67.6 \%)$ girls .

In the study of [7], the overall prevalence of UTI in older children ( $\leq 19$ years) with or without fever is reported to be $7.8 \%$.

In the study of [10], in Nnewi in Nigeria the prevalence of significant bacteriuria among pediatric patients attending Nnamdi Azikiwe University Teaching Hospital is $8 \%$, This study showed that there was high incidence of UTI among the female gender $(66.67 \%)$ than the male gender $(33.33 \%)$.

Another study in Menoufiya Governorate in Egypt [11], Out of 500 children 314 (62.8\%) males and $186(37.2 \%)$ females, the prevalence of UTIs among children aged 3-12 years attending to Pediatric Outpatient Clinic in Menoufia University Hospital was (4.8\%).

However there was no agreement with the study of [12], in Sohag governorate in Egypt where the prevalence of UTIs among primary school children from five primary schools in different parts of the Sohag Governorate, was $0.6 \%$ for the initial urinary screening and $0.5 \%$ for the second screening. This is due to presence of many risk factors in our study that leading to this difference.

Results of the current study shows that there was statistically significant difference between males and females in relation to prevalence of UTI, where prevalence of UTI in female $54.8 \%$ (23 female from 42 one has UTI) while prevalence of UTI in male 45.2\% (19 male from 42 one has UTI) $(\mathrm{P}=0.014)$, the highest number of cases (31\%) was found among females in age group 5-7 years then among males $(28.6 \%)$ in age group $2-4$ years. This is due to presence of many risk factors in females more than in males.
Similar to our results, [8] Higher prevalence of UTI occurred in girls $(11.4 \%)$ than boys $(1.6 \%)$, with statistically significant difference between males and females in relation to prevalence of UTI.

In the study of [13] , There was statistically significant difference between males and females in relation prevalence of UTI among the screened children.

Results of the current study show statistically significant difference between Risk factors as Un circumcised males, Family history of UTI, Recurrent UTI, Enuresis, and Constipation in relation to prevalence of UTI, And statistical significant higher difference between Prolonged use of antibiotic in relation to prevalence of UTI.

In the study of [14], Nocturnal enuresis was highly significant to prevalence of UTI ( $\mathrm{P}=$ 0.035).

In the study of [15], the overall prevalence of enuresis was $6.8 \%$, the prevalence of urinary tract pathology was $2.9 \%$ among enuretics which indicates high association between UTI and nocturnal enuresis.

In the study of [16], Circumcised males appear to be at lower risk for developing UTI perhaps because of low perurethral and urethral bacterial inoculums, This may be due to the small number of males included in the study.

In the study of [17], reported that there were statistically significant difference between bed wetting and UTI. However, the association between UTI and previous history of UTI was insignificant $(\mathrm{P}>0.05)$.

In the study of [18], showed that female sex $(\mathrm{P}<0.05)$, constipation $(\mathrm{P}<0.001)$, not taking anthelmintic $(\mathrm{P}<0.001)$, lack of toilet training $(\mathrm{P}<0.001)$ and inadequate water intake $(\mathrm{P}<0.01)$ were significant risk factors for urinary tract infection in children.

Results of the current study show that Children with dipstick LE positive were 56 (9.3\%), nitrite positive were $47(7.8 \%)$ and both LE \& Nitrite positive were 17 (2.8\%). LE sensitivity is $(73.8 \%)$, specificity $(95.5 \%)$, negative predictive value (98\%), positive predictive value $(55.4 \%)$ and overall accuracy 
(94\%). Nitrite sensitivity is $(66.7 \%)$, specificity (96.6\%), negative predictive value $(97.5 \%)$, positive predictive value $(59.6 \%)$ and overall accuracy (94.5\%).Both Leukocyte esterase (LE) and nitrite sensitivity is (40.5\%), specificity (100\%), negative predictive value (95.7\%), positive predictive value (100\%) and overall accuracy $(95.8 \%)$.

Similar to our results [13], found that the sensitivity of the dipstick was $82.6 \%$, specificity was $98.9 \%$, positive predictive value was $79.1 \%$ and negative predictive value was $99.1 \%$. So dipstick is a good negative test rather being a good positive test for detection of UTI.

However, in the study of [6], found that Combined sensitivity of LE and Nitrite was $75.74 \%$ while specificity was $68.90 \%$. He concluded that urine dipstick test may be considered for rapid urinalysis to diagnose UTI.

In the study of [19], found that the sensitivity of leukocyte esterase test were $63.6 \%$ while the combined leukocyte esterase and nitrite test were $66.7 \%$. He concluded that the dipstick test can be used as a diagnostic tool in detecting UTI cases in ER to prevent potential sequel like hypertension and renal scarring.

In the study of [20], found that combined sensitivity of LE and Nitrite was $79.6 \%$, while sensitivity and specificity of LE were $73.5 \%$, $58.5 \%$ respectively and for Nitrite were $57.1 \%$, $78.7 \%$ respectively. He concluded that for faster diagnosis of UTI, dipstick tests for leukocyte esterase and nitrite test should be added in routine laboratory practices.

In the study of [11], found that LE sensitivity is $(85.8 \%)$, specificity $(54.1 \%)$, positive predictive value $(45.9 \%)$ and negative predictive value $(91.2 \%)$. Nitrite sensitivity is (79.3\%), specificity (66.3\%), positive predictive value $(73.9 \%)$ and negative predictive value $(88.9 \%)$. Leukocyte esterase (LE) and nitrite sensitivity is (71.2\%), specificity (100.00\%), positive predictive value $(100 \%)$ and negative predictive value $(79.4 \%)$.

Results of the current study show that according to culture, the most common infecting organism was E.coli that represent (76.2\%) followed by Klebsiella pneumonia (9.5\%), Enterococcus Faecalis (7.1\%), Proteus mirabilis $(4.8 \%)$ and coagulase -ve staphylococci in $(2.4 \%)$.

Similar to our results [21], The most common organisms responsible for Urinary Tract Infection (UTI) found were E Coli (47.6\%) followed by Klebsiella (23.2\%) and Proteus (10\%), Staphylococcus was found in $(7.3 \%)$ and Enterobacter in $(7.3 \%)$ children, and rest $(4.6 \%)$ were effected with other organisms.

In the study of [11], shows that according to culture, the infecting organism was E.coli in $(62.5 \%)$, Klebsiella in (12.5\%), Enterococcus Faecalis in $(16.7 \%)$ and coagulase -ve staphylococci in $(8.3 \%)$.

In the study of [22], The predominant bacterial isolate was E. coli $(56.8 \%)$, followed by S. aureus (18.9\%), Klebsiella spp. (16.2\%) and $\mathrm{P}$. aeruginosa $(8.1 \%)$.

In the study of [16], The most common urinary pathogens isolated were E.coli (63\%), Klebsiella pneumoniae (8\%) and Proteus mirabilis (8\%). Other pathogens included Pseudomonas auerogenosa (7\%), Staphylococcus aureus and Citrobacter 5\% each and Enterobacter and Coliform 2\% each.

In study of [13], The most common organism found in UTI cases culture was E coli (62 \%), Enterococcus faecalis (17.3\%), Klebsiella pneumonia (10.3\%), and Coagulase negative staphylococci(10.4\%)

Results of the current study show that according to antibiotic sensitivity, 12 (28.6\%) patients were sensitive to Cefotaxime, 11 (26.2\%) were sensitive to Amikacin, 6 (14.3\%) were sensitive to Amoxicillin and Clavulanic acid, $3(7.1 \%)$ were sensitive to Ceftriaxone, 3 (7.1\%) were sensitive to Co Trimoxazole, 3 (7.1\%) were sensitive to Imipenem, 2 (4.8\%) were sensitive to Ciprofloxacin and $2(4.8 \%)$ were sensitive to Nitrofurantoin.

Similar to our study of[11], shows that according to antibiotic sensitivity, (62.5\%) patients were sensitive to cefotaxime, (25\%) 
were sensitive to Amikacine and (12.5\%) were sensitive to Amoxicillin and clavulanic acid.

In the study of [23], The most common uropathogen in primary and recurrent UTIs is E. coli and cefazolin is the drug of choice for treating such infections in children.

In study of [16], Sensitivity of different urinary isolated to Amikacin was highest (82\%) followed by meropenem (75\%), tazocin $(61 \%)$ and Sulzone (58\%).

In the study of [24], Most of the organisms were highly sensitive to Nitrofurantoin and Amikacin. Sensitivity to quinolones and third generation Cephalosporins varied according to the organism. E. coli was $100 \%$ sensitive to Nitrofurantoin. E. coli was sensitive to ofloxacin, cefotaxim and amikacin in $94.4 \%, 94.7 \%$ and $94.7 \%$, respectively. E. coli was resistant to ampicillin in $91.6 \%$, cotrimoxazole in $66.6 \%$ and nalidixic acid in $63.6 \%$.

\section{CONCLUSION AND RECOMMENDATIONS:}

We conclude that the prevalence of UTI in our study was $7 \%$. Risk factors of UTI in children in our study were Un circumcised males, prolonged use of antibiotics, Family history of UTI, Recurrent UTI, Enuresis, and Constipation.

E. Coli was the most common pathogen that causes UTI in children included in our study. Cefotaxime and Amikacin identified as the common antibiotic sensitive to the isolates, Further studies must be done in large population overall Egypt to help in determination of local causative organisms and preventive measures to decline the prevalence of UTI by knowing the predisposing factors and preventing it .

Use of dipstick test decrease patient's time and money, and may also help in earlier initiation of treatment.

\section{Proposed application:}

Determination the UTI prevalence and the causative organisms and contributing factors help in early and good management with it.

\section{Study Limitations:}

Our study is small sample size, not cover large population but it may be considered as a base for other advanced studies.

Acknowledgement The authors are grateful for the patients without them this study would not achieved.

\section{Declaration of interest}

The authors report no conflicts of interest. The authors alone are responsible for the content and writing of the paper.

\section{Funding information:}

None declared

\section{REFERENCES}

1 - Oh, M. M., Cheon, J., Kang, S. H., Park, H. S., Lee, J. G., \& Moon, D. G. Predictive factors for acute renal cortical scintigraphic lesion and ultimate scar formation in children with first febrile urinary tract infection. The Journal of urology, (2010) 183(3), 1146-1150.

2 - Craig, J. C., Simpson, J. M., Williams, G. J., Lowe, A., Reynolds, G. J., McTaggart, S. J., ... \& Irwig, L. M.. Antibiotic Prophylaxis and Recurrent Urinary Tract Infection in Children (vol 361, pg 1748, 2009). New England Journal of Medicine (2010) , 362(13), 1250-1250.

3 - Mansoor, I. Y., AL-Otraqchi, K. I., \& Saeed, C. H. Prevalence of urinary tract infections and antibiotics susceptibility pattern among infants and young children in Erbil city. Zanco Journal of Medical Sciences (2015)., 19(1), 915-922.

4 - White, B. Diagnosis and treatment of urinary tract infections in children. American family physician (2011), 84(7): 771.

5 - Colgan, R., \& Williams, M.. Diagnosis and treatment of acute uncomplicated cystitis. American family physician(2011), 84(7), 771.

6 - Najeeb, S., Munir, T., Rehman, S., Hafiz, A., Gilani, M., \& Latif, M.. Comparison of urine dipstick test with conventional urine culture in diagnosis of urinary tract infection. J Coll Physicians Surg Pak(2015), 25(2), 108-110.

7 - Shaikh, N., Morone, N. E., Bost, J. E., \& Farrell, M. H. Prevalence of urinary tract infection in childhood: a meta- 
analysis. The Pediatric infectious disease journal(2008), 27(4), 302-308.

8 - Mohammed, A., Abdelfattah, M., Ibraheem, A., \& Younes, A.. A study of asymptomatic bacteriuria in Egyptian school-going children. African health sciences(2016), 16(1), 69-74.

9 - Durmišiević-Serdarević, J., Durmišević, S., Lelić, M., Durmišević, J., \& Uzunović, S.. Urinary tract infections in preschool children. Medicinski Glasnik(2013), 10(1).

10 - Akujobi, C. N., Ezeanya, C. C., EmekaOkafor, K. M., \& Ebenebe, J. C.. A study on significant bacteriuria among children attending the out-patient clinic of a university teaching hospital, Nigeria. International Journal of Microbiology Research(2013), 5(4), 448.

11 - Abd El-Ghaffar, W. A., Mohammed, F. E., Sameh, A. Prevalence of Urinary Tract Infection in Children Attending Pediatric Outpatient Clinic in Menoufia University Hospital. (2016)

12 - Mahmoud, R. A., Al-zahraa, E., Mohammad, R. S., \& Yousef, F. MUrinary Screening for Detection of Renal Abnormalities in Asymptomatic School Children, Sohag Governorate, Egypt. .(2016).

13 - El-Shafie, A. M., El-Nemr, F. M., Bahbah, M. B., Shokry, M., \& Attia, A. The role of urine screening (in school children of Menoufiya Governorate) in early detection of renal disorders. Journal of American Science(2014), 10, 143-150.

14 - Sawalha, R. M. H. Prevalence of urinary tract infection among children of primary schools in Nablus (Doctoral dissertation). (2009).

15 - Safarinejad, M. R.. Prevalence of nocturnal enuresis, risk factors, associated familial factors and urinary pathology among school children in Iran. Journal of pediatric urology(2007), 3(6), 443-452.

16 - Afridi, J. K., Afridi, M. A., Karim, R., \& Munir, A. Causative organisms and their sensitivity pattern of urinary tract infection in children of tertiary care hospital. KJMS(2014)., 7(2), 291.

17 - Isa, M. A., Ismail, H. Y., Allamin, I. A., Shettima, A., \& Mustapha, A.. Prevalence of urinary tract infection among primary school children in Maiduguri, Borno State, Nigeria. International Journal of Environment(2013), 2(1), 9-15.

18 - Hossain, M., Akter, R., Mannan, K., Ahmed, M., Deb, K., \& Mostafa, G.. Risk Factors of Febrile Urinary Tract Infection in Children. Urol Nephrol Open Access $\mathrm{J}(2015), 2(5), 1-5$.

19 - Laosu-angkoon, S. The sensitivity and specificity of a urine leukocyte esterase dipstick test for the diagnosis of urinary tract infection in the outpatient clinic of Rajavithi Hospital. Journal of the Medical Association of Thailand $=$ Chotmaihet thangphaet(2013), 96(7), 849-853.

20 - Taneja, N., Chatterjee, S. S., Singh, M., Sivapriya, S., Sharma, M., \& Sharma, S. K. Validity of quantitative unspun urine microscopy, dipstick test leucocyte esterase and nitrite tests in rapidly diagnosing urinary tract infections. J Assoc Physicians India(2010), 58, 485-7.

21 - Lehrasab, W., Aziz, T., Ahmed, N., \& Ahmed, I. Causative Organisms of Urinary Tract Infection and their Sensitivity Pattern in Children. Annals of PIMS ISSN, 1815, 2287.

22 - Dada, E. O., \& Aruwa, C. E.. Asymptomatic Bacteriuria Prevalence among Primary School Children in the Federal University of Technology, Akure (Futa), Ondo State. Nigeria Journal of Applied Life Sciences International(2016), 4, 1-8.

23 - Wu, T. H., Huang, F. L., Fu, L. S., Chou, C. M., Chien, Y. L., Huang, C. M., ... \& Chen, P. Y. Treatment of recurrent complicated urinary tract infections in children with vesicoureteral reflux. Journal of Microbiology, Immunology and Infection(2016), 49(5), 717-722 
24 - Sharma, A., Shrestha, S., Upadhyay, S., \& Rijal, P.. Clinical and bacteriological profile of urinary tract infection in children at Nepal Medical College Teaching Hospital. Nepal Med Coll J(2011), 13(1), 24-26.

To Cite This Article: Ali MA, Ezzat KA, Abd El Rahman IK ${ }^{*}$. Epidemiology of urinary tract infections in the
children in zagazig university children's hospital.ZUMJ 2019;25(6);909-918.DOi:
$\begin{aligned} & \text { 10.21608/zumj.2019.10879.11320. }\end{aligned}$

